\title{
A mixed-methods evaluation of a community pharmacy signposting service to a commercial weight-loss provider
}

\author{
Jackie Inch ${ }^{1, *}$, Alison Avenell ${ }^{2}$, Lorna Aucott ${ }^{3}$ and Margaret C Watson ${ }^{4}$ \\ ${ }^{1}$ Centre of Academic Primary Care, University of Aberdeen, Polwarth Building West Block, Foresterhill, Aberdeen \\ AB25 2ZD, UK: ${ }^{2}$ Health Services Research Unit, University of Aberdeen, Aberdeen, UK: ${ }^{3}$ Medical Statistics Team, \\ Institute of Applied Health Sciences, University of Aberdeen, Aberdeen, UK: ${ }^{4}$ Department of Pharmacy and \\ Pharmacology, University of Bath, Bath, UK
}

Submitted 8 March 2017: Final revision received 21 February 2018: Accepted 2 March 2018: First published online 23 April 2018

\begin{abstract}
Objective: Community pharmacies could provide access for clients to commercial weight management organizations. We evaluated recruitment, referral and outcomes of adults provided with free vouchers by community pharmacies to attend Scottish Slimmers classes.

Design: Prospective cohort design with qualitative interviews with clients and pharmacy personnel. Scottish Slimmers collected weight and attendance data.

Setting: Pharmacies in Aberdeen City, Scotland.

Subjects: Clients aged $\geq 18$ years with $\mathrm{BMI} \geq 30 \mathrm{~kg} / \mathrm{m}^{2}$.

Results: Ten of twenty-three pharmacies were recruited; eight successfully recruited clients. Of 129 clients recruited, ninety-seven (75\%) attended at least one class and fifty-one ( $40 \%$ ) attended all twelve classes. At baseline, clients' mean weight was 99.4 (sD 17.5) $\mathrm{kg}$, mean BMI was $37 \cdot 8$ (sD 6.0) $\mathrm{kg} / \mathrm{m}^{2}$. After 12 weeks, mean weight change was $-3.7 \%$ (last observation carried forward) or $-2 \cdot 8 \%$ (baseline observation carried forward) for all ninety-seven clients. Client interviews indicated that many individuals would have not addressed their weight problems if this referral service had not been available. They had positive attitudes towards the pharmacy signposting service, attributed to the use of consultation rooms for privacy, receiving professional service from personnel and ongoing support and encouragement. The free provision of 12-week access facilitated participation. Service providers had positive attitudes and indicated their willingness to provide this service in future.

Conclusions: Community pharmacies could be used to increase access to weight management services, with pharmacy personnel providing additional support to clients. Future provision of pharmacy referral schemes should be evaluated on a larger scale with an economic evaluation.
\end{abstract}

Keywords
Pharmacies
Obesity
Weight loss
Overweight and obesity presents a major public health challenge to the current and future health of the population. The most recent Scottish Health Survey showed that $65 \%$ of adults in Scotland were overweight and $27 \%$ were obese. It is predicted that by 2030 over $40 \%$ of adults will be obese ${ }^{(1)}$. Higher BMI is associated with an increased risk of morbidity and mortality from a range of conditions including hypertension, heart disease, stroke, type 2 diabetes and several cancers ${ }^{(2)}$. In 2011 it was predicted that there were 100000 obese adults in Grampian, 55170 of whom were on the register held though the Quality and Outcomes Framework system ${ }^{(3)}$.

To tackle this major public health problem, NHS Grampian sought to commission a feasibility study of a commercial weight management service for adults with a
BMI of $\geq 30 \mathrm{~kg} / \mathrm{m}^{2}$, to help them to achieve and maintain a healthier weight. The study was conducted in Aberdeen city centre and suburbs. Aberdeen is situated in the North East of Scotland. Of the 283 data zones in Aberdeen, nine are among the most deprived of all Scottish data zones ${ }^{(4)}$. Less than $8 \%$ of the total city population lives in data zones representing the most deprived $20 \%$ of the Scottish population $^{(4)}$.

The present study explored the feasibility of a community pharmacy-based referral service to a commercial weight management service, Scottish Slimmers (SS). SS was founded in 1980 and has a proven record of enabling successful weight loss. It is a lifestyle-based, group weightloss programme which offers weekly meetings at community venues, a nutritionally balanced eating plan and 
advice on physical activity, aiming to produce moderate weight loss ${ }^{(5)}$. We hypothesized that the provision of this signposting service through community pharmacies could increase access to this weight management service. Community pharmacies in Scotland are involved in a number of formal signposting initiatives like optometry referrals $^{(6)}$, as well as out-of-hours services such as dental care included within the minor ailment service ${ }^{(7)}$. They can also refer patients to other social care providers, for example for child protection issues ${ }^{(8)}$.

The Scottish population regularly attends community pharmacies, with $85 \%$ of the population in Scotland using pharmacies in Scotland within a year ${ }^{(9)}$.

The purpose of the weight management signposting study was to assess the feasibility of community pharmacists providing a weight management signposting service. Specifically, we wanted to:

1. compare the uptake of a pharmacy-based signposting service;

2. compare retention rates of clients signposted through pharmacies;

3. compare the effect of different models of voucher provision on retention and weight;

4. explore the effect of a pharmacy-based signposting service on client weight;

5. explore clients' opinions regarding the provision of the signposting service; and

6. explore pharmacy staff members' experience of providing a pharmacy-based signposting service.

\section{Methods}

The feasibility study used a prospective cohort design and included qualitative interviews with clients and pharmacy personnel. SS collected weight and attendance data. The setting was community pharmacies in Aberdeen City, Scotland. The study was conducted between November 2013 and June 2014. Ethical approval was given by the College of Life Sciences and Medicine Ethics Review Board, University of Aberdeen.

\section{Pharmacies}

Using the local Health Board register, community pharmacies in Aberdeen City that were in close proximity (20 minutes' walking distance) to SS classes were identified. To be eligible to participate, pharmacies were required to have a private consultation room. Each pharmacy was provided with promotional materials relating to the referral service. Pharmacies received a payment of $£ 50$ to participate as well as $£ 5$ per client recruited.

\section{Client recruitment}

Each pharmacy had a recruitment target of twenty clients. Inclusion criteria for clients were age $\geq 18$ years and BMI $\geq 30 \mathrm{~kg} / \mathrm{m}^{2}$. Women who were pregnant, adults with eating disorders, or people attending community or commercial weight management groups in the previous three months were not eligible.

All members of pharmacy staff were trained to recruit clients. A researcher (J.I.) provided on-site training to the responsible pharmacist and available staff. The pharmacists then trained the remaining staff who were unavailable. Training involved the process for recruiting clients, measuring the clients' BMI, voucher allocation and data collection.

Once trained, pharmacy staff approached potentially eligible clients if they: (i) purchased weight-loss products; (ii) asked for advice about weight loss; or (iii) enquired about the study as a result of promotional information displayed in the community pharmacies.

All clients who expressed an interest in participating were provided with an information sheet after discussion with a member of pharmacy staff regarding whether there was a suitable SS class they could attend. Potential participants had their weight and height measured to calculate their BMI. If their BMI was $\geq 30 \mathrm{~kg} / \mathrm{m}^{2}$, the client was invited to participate. Clients were advised that if they had any concerns regarding their health they were to contact their general practitioner regarding their suitability to participate. Clients with a BMI of $<30 \mathrm{~kg} / \mathrm{m}^{2}$, thus not eligible for the present study, were advised of the nearest SS class.

Voucher allocation was initially randomized by client uptake to explore what effect, if any, this would have on class attendance, with the hypothesis that more frequent contact with the pharmacy might achieve more consistent class attendance. As such, consecutive clients were offered vouchers in one of three ways: (i) twelve vouchers provided at the recruitment visit; (ii) weekly vouchers issued every week for 12 weeks; or (iii) four vouchers issued on three occasions.

If clients were unable to collect vouchers on a weekly or monthly basis however, they were given all twelve vouchers at the recruitment visit. Voucher allocation was recorded in the client pharmacy log by pharmacy personnel. The original recruitment period was from April 2014 to July 2014. However, due to lower-than-anticipated recruitment from some pharmacies, the recruitment period was extended until the end of August 2014, with some pharmacies agreeing to recruit more than twenty clients (Fig. 1).

\section{Quantitative data sources}

Client characteristics

Pharmacy staff recorded clients' names, addresses, telephone contact details, weight, height, voucher serial numbers, date of collection of vouchers and obtained client consent. These details were recorded in the client pharmacy log, which was stored securely. A record was also kept of the number of clients who declined 


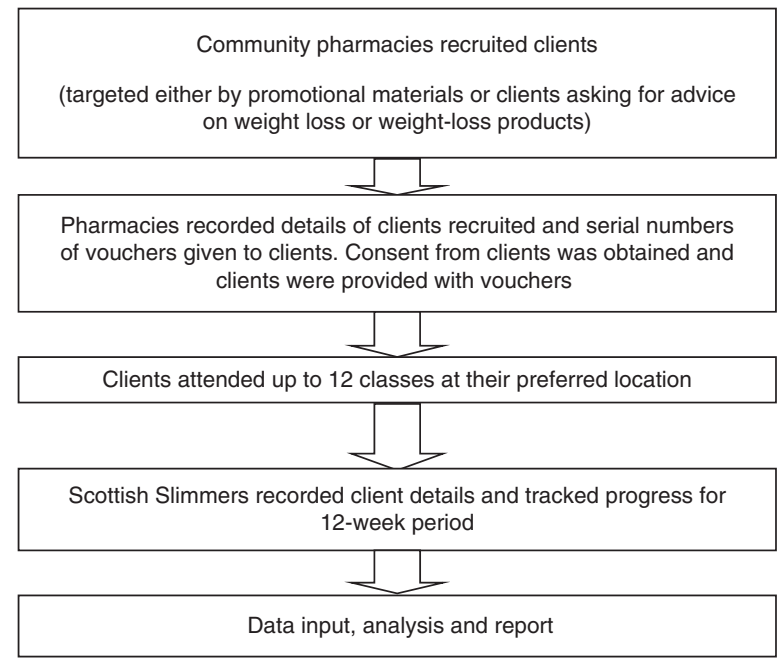

Fig 1 Client recruitment process for the present study evaluating a community pharmacy signposting service to a commercial weight-loss provider

participation and, if known, the reason for refusal. Clients who wished to think about participation were invited to return later. If they did not return within the duration of the study, they were categorized as a 'refusal'.

\section{Weight measurement and attendance at Scottish Slimmers' classes}

SS also recorded client contact details, calculated BMI, logged dates attended, client weight and voucher serial numbers. These details were stored securely by the SS coordinator. NHS Grampian personnel liaised with SS and the research team to facilitate data collection and provision. The Scottish Index of Multiple Deprivation (SIMD; http://www.gov.scot/Topics/Statistics/SIMD, Scottish Datazone version) was calculated using each client's postcode.

\section{Quantitative outcome measures}

Quantitative outcome measures were the following:

1. the number of clients who were offered/requested the service;

2. the number of clients who consented to use the service;

3. persistence of client attendance at SS classes; and

4. weight changes of clients referred from the community pharmacy-based service.

\section{Analysis}

The quantitative data derived from clients and pharmacies were entered into a database in the statistical software package IBM SPSS Statistics version 22, with a $10 \%$ accuracy check being performed by a member of the department administrative staff (H.R.). The data were analysed using descriptive statistics. We analysed weight change data with the last observation carried forward ${ }^{(10)}$ and the baseline observation carried forward ${ }^{(11)}$ to take account of missing data.

\section{Qualitative data sources}

Client experience of the referral service

Telephone interviews were conducted with clients, based on voucher allocation. A random sample of clients was selected $^{(12)}$ from each of the three voucher allocation methods and those contactable by telephone were interviewed to explore their attitudes and opinions about the future delivery of the service.

Written consent to participate in an interview was obtained at the point of recruitment. Verbal consent was sought prior to starting the interview, which was recorded with each client's consent.

Pharmacy staff members' experience of the referral service Pharmacy personnel were given the option of either attending a focus group or participating in a telephone interview to explore their experience of the service and to obtain suggestions for future service delivery. The intention was to derive evidence from each of the participating pharmacies.

\section{Qualitative outcome measures}

Qualitative outcome measures were the following:

1. client experience of, and satisfaction with, the referral service; and

2. pharmacist and pharmacy support staff experience of, and satisfaction with, the provision of the service.

\section{Analysis}

The qualitative data were digitally recorded, transcribed verbatim by a research secretary and checked for accuracy by the researcher (J.I.). Thematic analysis of the transcripts was performed using the themes included in the topic guide, as well as newly emergent themes (by J.I.).

\section{Results}

Of the twenty-three community pharmacies invited, ten consented to participate, five of which were situated in deprived areas (SIMD score $=1-2$; Table 1 ). Of the 145 clients enquiring about the service, sixteen were excluded due to age, BMI or health reasons (Fig. 2). Of the 129 clients recruited, ninety-seven attended at least one SS class.

Eight of the ten pharmacies recruited clients to the service. Of these eight pharmacies, three recruited fewer than ten clients while the remainder either met or exceeded the original recruitment target ( $n$ 20). In all but one pharmacy, the weight management service was delivered by either the pharmacist or other pharmacy staff (i.e. dispensing technician, pre-registration student or a pharmacy manager). In the remaining pharmacy, the service was delivered solely by non-pharmacist personnel (i.e. pharmacy counter staff). Client demographics are presented in Table 2. Most participants were female; $6 \%(n 6)$ were 
Table 1 Characteristics of the pharmacies participating in the community pharmacy signposting service to a commercial weight-loss provider, Aberdeen City, Scotland, November 2013-August 2014

\begin{tabular}{|c|c|c|c|c|c|c|c|c|}
\hline $\begin{array}{l}\text { Pharmacy } \\
\text { ID }\end{array}$ & Type & SIMD & Location & $\begin{array}{l}\text { Personnel who delivered } \\
\text { signposting service }\end{array}$ & $\begin{array}{l}\text { No. of clients } \\
\text { excluded }\end{array}$ & $\begin{array}{l}\text { No. of clients } \\
\text { recruited }\end{array}$ & $\begin{array}{l}\text { No. of clients } \\
\text { attending a minimum } \\
\text { of one SS class }\end{array}$ & $\begin{array}{l}\text { No. of clients } \\
\text { with SIMD } \\
\text { score }=1-2\end{array}$ \\
\hline 01 & Small chain & 3 & City suburb & $\begin{array}{l}\text { Pharmacist/pre-registration } \\
\text { pharmacist }\end{array}$ & 2 & 25 & 19 & 13 \\
\hline 02 & Large multiple & 5 & City suburb & Pharmacist/pharmacy manager & 3 & 20 & 18 & 2 \\
\hline 03 & Independent single outlet & 2 & City suburb & Pharmacist & 2 & 4 & 1 & 0 \\
\hline 04 & Small chain & 1 & City suburb & $\begin{array}{l}\text { Pharmacist/pre-registration } \\
\text { pharmacist }\end{array}$ & 0 & 5 & 3 & 3 \\
\hline 05 & Small chain & 3 & City suburb & Pharmacist & 3 & 8 & 7 & 4 \\
\hline 06 & Small chain & 1 & City suburb & Pharmacist/staff & 1 & 21 & 15 & 9 \\
\hline 07 & Independent single outlet & 1 & City suburb & Pharmacist/dispensing technician & 0 & 20 & 17 & 14 \\
\hline 08 & Large multiple & 5 & City suburb & Pharmacy staff & 5 & 25 & 16 & 6 \\
\hline 09 & Independent single outlet & 5 & City centre & Pharmacist & 0 & 0 & 0 & 0 \\
\hline 10 & Large multiple & 2 & City centre & Pharmacist/pharmacy staff & 0 & 1 & 1 & 0 \\
\hline
\end{tabular}

SIMD, Scottish Index of Multiple Deprivation (SIMD score $=1$, most deprived; SIMD score $=5$, most affluent); SS, Scottish Slimmers; small chain, $>10$ pharmacies; large multiple, $>30$ pharmacies.

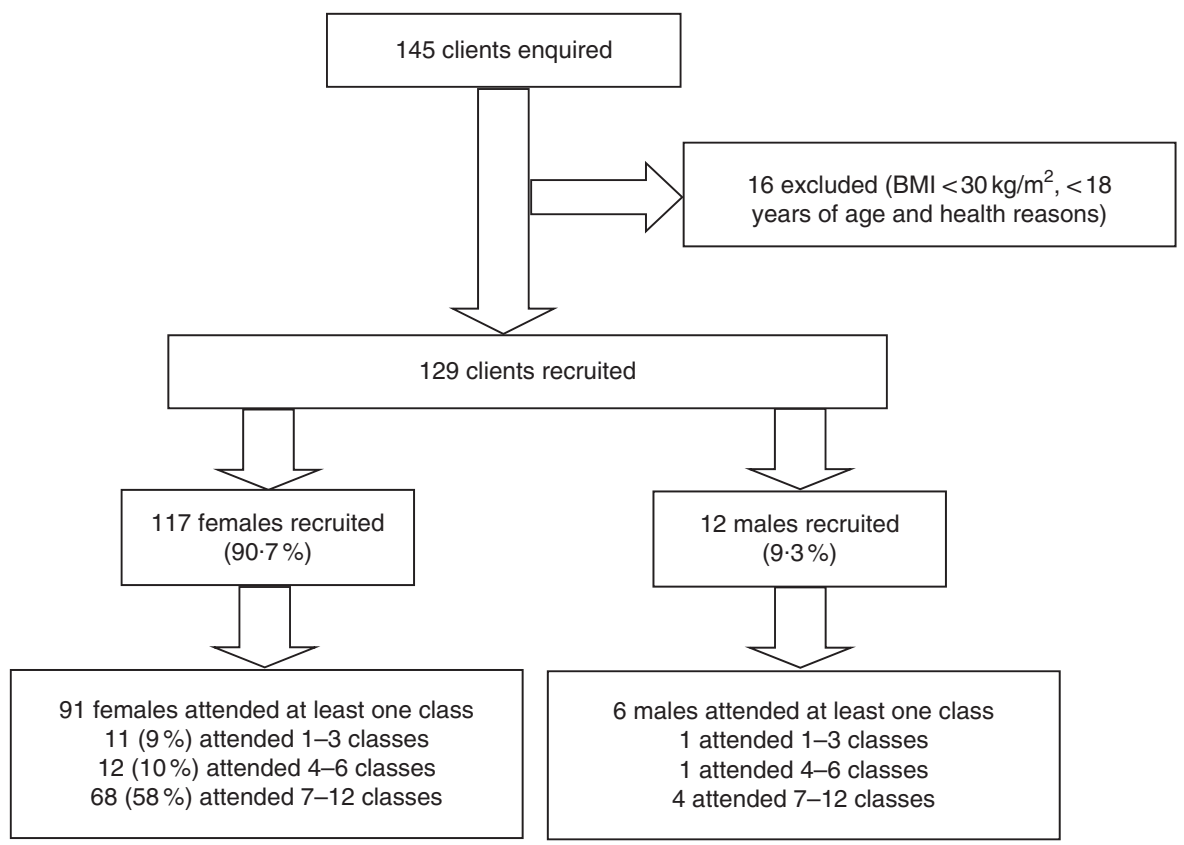

Fig. 2 Flowchart detailing client retention for the present study evaluating a community pharmacy signposting service to a commercial weight-loss provider

male. Most clients who attended the SS classes were between 40 and 70 years of age and over half of attendees $(53 \%, n 51)$ lived in more deprived areas of Aberdeen. The majority of clients $(63 \%, n 61)$ attended a class within $7 \mathrm{~d}$ of recruitment. Most clients had visited the pharmacy before; but for six clients recruitment occurred on their first visit to the community pharmacy. Nearly $40 \%$ ( $n$ 38) of clients who attended classes had visited the pharmacy to ask for advice regarding weight loss or to sign up for the service. Most clients ( $63 \%, n$ 58) opted to receive all twelve vouchers at one time, with $28 \%$ ( $n$ 26) and 9\% ( $n$ 8) opting for monthly and weekly supply, respectively.

Small chain pharmacies (pharmacies with fewer than ten stores) recruited the most clients ( $n$ 39) from deprived areas. Independent single-outlet pharmacies recruited most clients living in more affluent areas ( $n$ 20). Over $50 \%$
( $n$ 51) of clients who participated lived in areas with SIMD score of 1 or 2 (i.e. most deprived areas).

The median number of classes attended was 12 (interquartile range $=6 \cdot 5-12$ ). Fifty-one clients (53\%) attended all twelve classes. Women were more likely to attend seven to twelve classes compared with men: sixty-eight women $(58.1 \%$ of those recruited) $v$. four men $(33.3 \%$ of those recruited).

At baseline, the mean weight of clients was 99.4 (SD 17.5) $\mathrm{kg}$ and their mean BMI was 37.8 (SD 6.0) kg/m². All clients had a BMI calculated at their community pharmacy of $\geq 30 \mathrm{~kg} / \mathrm{m}^{2}$; however, four had a BMI $<30 \mathrm{~kg} / \mathrm{m}^{2}$ based on their measurements taken at an SS class. For the ninetyseven clients who attended at least one class, mean weight change calculated using the last observation carried forward was -3.70 (sD 8.43) $\mathrm{kg}$ over the 12 -week period, 
Table 3 Weight change characteristics over a 12-week period of clients $\left(n 97^{*}\right)$ participating in the community pharmacy signposting service to a commercial weight-loss provider, Aberdeen City, Scotland, November 2013-August 2014

\begin{tabular}{lcc}
\hline Weight change characteristic & LOCF & BOCF \\
\hline Weight change $(\mathrm{kg})$ & & \\
Mean & -3.70 & -2.86 \\
SD & 8.43 & 8.43 \\
Weight change (\% of initial weight) & -3.7 & -2.8 \\
Mean & 3.69 & 3.65 \\
SD &
\end{tabular}

LOCF, last observation carried forward; BOCF, baseline observation carried forward.

*One hundred and twenty-nine clients were recruited, but ninety-seven attended classes.

representing a mean weight loss of $-3.7 \%$ of initial weight (Table 3). The mean weight change using the baseline observation carried forward was -2.86 (SD 8.43) $\mathrm{kg}$ and this represented $-2 \cdot 8 \%$ of initial weight. Additionally, $34 \%$ ( $n$ 35) of clients lost $5 \%$ of their body weight and four lost $10 \%$ over 12 weeks.

\section{Client interviews}

Twenty clients were randomly selected for a telephone interview, of whom thirteen were interviewed. Eight interviewees received all their vouchers at the start, four received monthly vouchers and one client obtained vouchers on a weekly basis. Three of the clients interviewed had never attended classes. The ten remaining clients had varying attendance. Six clients attended twelve classes and continued to attend classes (self-payment). One client mentioned that she had completed the twelve free classes but could not afford to attend further classes. Three clients were still attending classes and indicated that they intended to complete all twelve classes. Illustrative quotes are presented for clients' attitudes and opinions of the service in Table 4. Quotes include a code that incorporates each client's identification number, voucher allocation method, weight change and interview quote line number.

Awareness of the scheme was mostly derived through promotional materials displayed in the pharmacies. Three clients indicated they had become aware of the study through word of mouth from family or friends. Most clients stated that they signed up for the study immediately. One male client stated he needed some time to think about it before he signed up.

Reasons for deciding to take part in the scheme were influenced by other health problems. Specific health issues included leg ulcers, diabetes, raised blood sugar levels, increased blood pressure, heart problems and arthritis.

The free availability of the classes appeared to be an incentive to enrol in the study. For some clients, their decision to participate was a spur-of-the-moment decision and others spoke about peers (family members, friends) attending SS classes and this was an incentive to participate. 
Table 4 Clients' and pharmacists' attitudes and opinions of the community pharmacy signposting service to a commercial weight-loss provider

\begin{tabular}{|c|c|}
\hline Theme & Quote \\
\hline \multicolumn{2}{|l|}{ Clients } \\
\hline Awareness of scheme & $\begin{array}{l}\text { C2-1 (All, }-6 \cdot 8 \mathrm{~kg} \text { ): 'I went into the local chemist, to pick up my prescription, and saw the leaflet there and I thought, right, okay, } \\
\text { let's go for it, let's just take the bull by the horns and let's do it.' }\end{array}$ \\
\hline Decision to use service & $\begin{array}{l}\text { C2-3 (All, }-5.2 \mathrm{~kg} \text { ): 'I did it first and foremost because I am overweight, and I just felt that the time was right for me to do it then. } \\
\text { I had a few health problems, ... I had an ulcer on my leg ... and I thought no, this is the time to do it, and let's go for it. I saw } \\
\text { that it was NHS and it was } 12 \text { weeks free, and I thought let's just do it now.' }\end{array}$ \\
\hline Facilitators & $\begin{array}{l}\text { C3-7 (Monthly, }-9.5 \mathrm{~kg} \text { ): 'I've been to Scottish Slimmers and slimming clubs, eh years and years ago, and I just thought, every } \\
\text { time I try to do it myself, eh you always fall back, ... and I just, when I saw it there, and also I'll tell you what it was, because } \\
\text { the first } 12 \text { weeks were free, that was another incentive to do it.' }\end{array}$ \\
\hline Reasons for non-attendance & $\begin{array}{l}\text { C9-6 (All, non-attender): 'I was going through a bad patch with my partner, ... stress, not in the right head space and then I got } \\
\text { the flu thing that was going about, em, it's always next week, I need somebody to hold my hand for the first time as well, it's } \\
\text { quite hard.' }\end{array}$ \\
\hline Experience of service & $\begin{array}{l}\text { C8-24 (Monthly, }-8 \cdot 6 \mathrm{~kg}) \text { : 'It wasn't like a consultation, ... it was how you getting on ... actually the girl saw me today, I was in } \\
\text { getting a prescription, and she said how you getting on with your, and l'd told her what l'd lost, and she was quite delighted.' } \\
\text { C2-14 (All, }-5 \cdot 2 \mathrm{~kg} \text { ): 'She was very professional, she was very good, in the way she said, look I'm sorry, I have to ask this, I } \\
\text { have to know, but she was very, very good, she, she really made me feel at ease, I didn't feel at any time that I was under } \\
\text { any kind of pressure.' }\end{array}$ \\
\hline Voucher allocation & $\begin{array}{l}\text { C2-19 (All, }-5 \cdot 2 \mathrm{~kg} \text { ): 'I was very happy with how I got my vouchers, because it's like every week, and I just think I am a working } \\
\text { mum, and it would have been too much of a palaver to be getting off the bus, going in, getting my voucher, getting back on } \\
\text { the bus, going to my slimming class.' }\end{array}$ \\
\hline Cost of service & C8-27 (Monthly, $-8.6 \mathrm{~kg}$ ): 'It's convenient, it was free, ... eh basically it was an incentive to get started.' \\
\hline $\begin{array}{l}\text { Improvements to signposting } \\
\text { service }\end{array}$ & $\begin{array}{l}\text { C8-29 (Monthly, }-8.6 \mathrm{~kg} \text { ): 'Maybe if there had been a few leaflets lying about, might encourage more people just to pick up the } \\
\text { leaflet and go away with it.' } \\
\text { C6-24 (All, }-6 \cdot 3 \mathrm{~kg} \text { ): 'If your BMl is still above the } 30 \text {, if you could, if it would be possible to offer a bit longer, the tokens.' }\end{array}$ \\
\hline Other & $\begin{array}{l}\text { C1-33 (All, }-6.8 \mathrm{~kg} \text { ): 'I would have never thought of going to my GP, ... you know, I sort of needed to lose weight type thing, ... } \\
\text { you prioritize your GP for other things.' }\end{array}$ \\
\hline \multicolumn{2}{|l|}{ Pharmacists } \\
\hline Reason for participation & P4-1: 'We thought it may, obviously assist our local patients.' \\
\hline Service delivery & $\begin{array}{l}\text { P2-2: 'The staff would do the initial consultation ... at the health counter, ... and then they would usually pass it forward to, } \\
\text { usually myself or another pharmacist.' } \\
\text { P6-2: 'We trained all four of them up [pharmacy staff], so that they were aware of what the paperwork they needed to } \\
\text { complete, ... the pharmacist can't do all of it, you know.' }\end{array}$ \\
\hline Voucher allocation & P7-8: 'I didn't mind how we gave out the vouchers, but the customers definitely preferred to have them all at once.' \\
\hline Promotional material & $\begin{array}{l}\text { P2-15: 'I thought they were really good, that was what brought the people in, we put one out at like the front door and we put } \\
\text { some up beside the pharmacy.' }\end{array}$ \\
\hline $\begin{array}{l}\text { Impact on pharmacy } \\
\text { workload }\end{array}$ & $\begin{array}{l}\text { P2-8: 'If it was getting rolled out to a lot of patients, ... that would need to be taken into account, because we ended up with } \\
\text { about twenty patients, which wasn't too bad, em, because obviously the initial appointment bit took a bit longer, but when } \\
\text { they were coming in to collect their vouchers and just having a quick chat, ... once you had them registered, it wasn't } \\
\text { difficult.' }\end{array}$ \\
\hline Training & P1-12: 'We were just signposting, you know, sending people to the right place, so yeah, no the training was fine.' \\
\hline Payment & P7-5: 'Slightly low as paid £30 for Stop Smoking consultation.' \\
\hline $\begin{array}{l}\text { Improvements to signposting } \\
\text { service }\end{array}$ & $\begin{array}{l}\text { P2-9: 'How it would be communicated between ... obviously like the community pharmacy and maybe the doctors so that they } \\
\text { knew the patients were, you know, doing the trial.' }\end{array}$ \\
\hline
\end{tabular}

GP, general practitioner.

At the time of interview, three clients had not attended a class. The reasons for non-attendance ranged from changes to personal circumstances, illness or holiday, to the friends they had signed up with not attending the classes.

Some clients were unsure of who they had initially spoken to regarding the study. The majority thought they had initially spoken to pharmacy counter staff. Two clients had been given appointments to return to discuss with the pharmacist and enrol in the study. Privacy was mentioned by two clients within the context of their experience of the service. One client stated that she would not have liked to ask or discuss the study if there had been other people waiting in the pharmacy. Most clients reported that they had been taken into a consultation room to discuss the study and to be weighed to assess their eligibility for the study. These clients indicated that this was a satisfactory arrangement. One client stated that if there had not been a private area she would not have taken part in study. Clients commented that pharmacy staff were supportive of their weight management attempts.
All the clients interviewed who had attended classes had lost weight, were complementary about the classes and appeared satisfied with their weight loss. There were comments on how encouraging and good the leaders were, as well as on the useful information they received. The majority of clients interviewed were happy to discuss their weight with pharmacy staff, primarily because they had been taken into the pharmacy consultation room. Another client indicated that she was initially embarrassed discussing her weight and there were other comments of 'nobody being comfortable' discussing their weight. All clients interviewed considered the pharmacy staff to be either very good or excellent in terms of professionalism.

Voucher allocation varied across the clients interviewed. There appeared to be a preference for vouchers to be allocated less frequently than weekly (i.e. monthly or all at once). When clients were asked if they intended to carry on with the classes, most of them stated that they would.

All interviewed clients considered had positive attitudes towards the signposting service. There were comments 
about clients being happy to approach pharmacy staff and it being a convenient service. A large number of the clients interviewed commented on the fact it was a free service. Two clients had negative comments regarding the service and this was about having to pay for classes after the initial 12-week service, even if they did not attend.

There were suggestions about how the service could be improved. One client suggested that more members of staff could have received training and several clients commented on how busy the pharmacy was and the need for more staff. Two clients thought that there could have been more leaflets available to take away and read. Several clients thought that more vouchers could be allocated if their BMI was rated as obese.

One client mentioned that she had not considered going to her general practitioner about her weight. The majority of clients stated that they probably would not have done anything about their weight and just carried on with their current eating habits, if this service had not been available.

\section{Pharmacy personnel interviews}

Five pharmacists and two dispensing technicians (from seven pharmacies) participated in a telephone interview. Table 4 presents pharmacists' attitudes and opinions of the service; the quotes include a code that incorporates each pharmacist's identification number and interview quote line number.

Reasons for participating included the importance of supporting research alongside the fact that obesity is a major health issue. One pharmacist commented on the 'local' issue of service provision and the idea of being able to help people with their weight management.

Pharmacies used different methods to deliver the service and some operated an appointment system. Some pharmacies considered appointment systems to be difficult due to unpredicted increases in workload.

In most instances, clients approached the pharmacy staff; however, one member of pharmacy staff mentioned having a discussion with a client about weight-loss medication and informing them about the service. In some pharmacies, the counter staff completed the entire consultation and they were confident to do this. Two pharmacists spoke of training all the pharmacy staff regarding the study.

Interviewees did not hold strong views regarding the different methods of voucher allocation. There were positive comments regarding the promotional material.

Most pharmacy staff reported that the referral service was not time-consuming, with most estimating around $10 \mathrm{~min}$ for the initial consultation. The administrative packs for clients also helped reduce workload. One pharmacist mentioned that twenty clients was a manageable number, but if it were to be expanded to more people there would need to be an appointment system.

All the pharmacists and pharmacy staff thought the training in groups was sufficient. When asked if individual staff training would have been a better option, comments were varied; some interviewees thought it would have been a good idea, but others did not consider it necessary. One pharmacist commented that if it was to be rolled out as an NHS service, it would be better to have a training evening.

Most pharmacists considered that the payment offered was adequate while one commented that it did not compare favourably with another service that they provided.

One pharmacist thought it would be good to inform the client's general practitioner of their participation in the service. There were two additional comments from pharmacists that the BMI chart utilized in the study was too low; that is, it did not provide higher BMI (e.g. $>40 \mathrm{~kg} / \mathrm{m}^{2}$ ) as a lot of clients had a BMI above this value.

Five out of seven of the pharmacy staff interviewed considered that the study had been a success because they had signed up several clients. Interviewees also spoke of clients coming back to the pharmacies to tell them how they were getting on. One staff member mentioned that clients seemed to like the idea that they were not limited to attending one class in a set location, they could choose to attend classes in other parts of the city.

Of the two pharmacies where no clients were recruited, one pharmacist thought it was because they could not promote the service enough; that is, it was company policy to display certain promotional material in prominent places only, such as window displays. The other pharmacist thought they were unsuccessful because they were unable to approach clients and none of their customers appeared interested.

Pharmacy staff appeared positive and willing to provide the service in the future. The interviewees from two pharmacies that recruited no clients stated they would be happy to provide the service in the future, although they would have to consider alternative promotional strategies.

\section{Discussion}

The present paper is the first published evaluation of a community pharmacy-based signposting service to a commercial weight management organization. This feasibility study is novel in that it assesses community pharmacies as a source of referring people who are obese to a weight management service. The service is also free of charge, which allows inclusion of all customers. The prospective, mixed-methods approach provided a holistic evaluation of this service. It was found that community pharmacy customers found this method of being referred to a commercial slimming organization acceptable and it is therefore a feasible option for health-care governing bodies to consider.

The main study limitations stem from the fact that it was a small-scale study run over a period of 12 weeks; therefore, the results may lack generalizability in terms of 
service providers and users. Community pharmacies were recruited from within Aberdeen City and therefore results may not be representative of the whole Scottish population, as more rural communities have not been included. Pharmacy personnel were unable to proactively recruit clients (due to constraints placed by the College Ethics Review Board) except in limited circumstances whereby customers enquired about weight-loss advice or products, and, as such, service uptake was mostly dependent upon customers approaching pharmacy staff. Due to time constraints, interviews were not completed with clients who attended only a few SS meetings.

Variation in client recruitment across pharmacies could be partially attributed to variable footfall. In addition, the non-recruiting pharmacies were situated in a city centre where customers might be more transient and possibly have less of a relationship with pharmacy staff. Two-thirds of participating clients visited their community pharmacy at least once per month; this may indicate that an existing relationship with a pharmacy may be beneficial in achieving service uptake ${ }^{(13)}$. The intention of the study was to focus on pharmacies in deprived areas in an attempt to reach clients. The SIMD value for a pharmacy will not necessarily reflect client SIMD and this is particularly true for city-centre pharmacies with high customer footfall. Despite these limitations, over half the clients who participated were from more deprived areas in Aberdeen City. Additionally, it is likely that uptake of the service will have been amplified due to the vouchers being free of charge. Men use pharmacies much less frequently than women $^{(14)}$ and only six male clients were recruited to the study.

Eligible clients were required to have $\mathrm{BMI} \geq 30 \mathrm{~kg} / \mathrm{m}^{2}$. Discrepant BMI values occurred with four clients between pharmacy and SS personnel, with the latter estimating BMI values of $<30 \mathrm{~kg} / \mathrm{m}^{2}$. This could be due to measurement error and/or it might be explained by the lag time between clients being recruited at pharmacies and the actual date they went to their first SS class; clients might have initiated weight loss prior to attending their first SS class.

The majority (63\%) of clients were given all twelve vouchers at baseline. Clients who were interviewed were not enthusiastic about collecting vouchers weekly but were more supportive of monthly collection.

Retention at SS classes was good, with fifty-one (53\%) clients. This rate compares favourably with previous studies, including studies of referring from primary care $\operatorname{organizations}^{(15,16)}$, and is considerably higher than community pharmacy studies evaluating standalone weight management services ${ }^{(14,17)}$.

The mean weight change achieved by clients across their twelve SS classes was $-2.86 \mathrm{~kg}$ using the baseline observation carried forward method. This equates to a loss of $2.8 \%$ of initial weight. These results are comparable with similar evaluations, namely signposting from a primary care organization to a commercial weight management organization ${ }^{(15,16)}$, and are better than standalone weight management methods ${ }^{(14)}$. Peer support has been shown to facilitate adherence to healthy eating plans $^{(18)}$ and clients in the present study mentioned support from pharmacy staff as helping with their weight management. The additional support that pharmacy staff provided, whether formal or informal, was highlighted by clients during interviews and may be an advantage of community pharmacies compared with other primary health-care providers whose interaction might be more time-restricted.

All clients interviewed had positive attitudes towards the signposting service and the SS classes (although three had not attended a class at the time of their interview). Interviewees indicated that they were aware they were overweight and some perceived that this was having a negative impact on their health. Despite this, the majority of interviewees stated they would not have taken action about their weight if they had not participated in the study. Two interviewees who had not attended a class had heard of the signposting service from a friend or family member, who had suggested they participate. The lack of engagement with the service by these clients may have been due to a lack of readiness to address their weight ${ }^{(19)}$.

Privacy was important to all interviewees and all were satisfied with their consultations taking place in a pharmacy consultation room. A number of clients interviewed indicated that further free provision of SS vouchers would be a good idea for those who had not reached their target weight or healthy BMI.

The community pharmacy staff interviewed were very positive about the study and indicated they would be happy to provide this type of service in the future. The signposting service was not perceived to have a substantial impact on workload.

\section{Conclusion}

In conclusion, the present study demonstrated the feasibility of providing a community pharmacy-based signposting service to a commercial weight management service. The signposting service was acceptable to both service users and providers. The effectiveness and costeffectiveness of this service need to be evaluated to explore whether it is viable adjunct to existing weight management services for obese patients.

\section{Acknowledgements}

Acknowledgements: The research team would like to thank all community pharmacies that participated, and all staff and participants involved with the study; Mrs Hazel Riley for transcribing the interviews; and David Ritchie from Research \& Data Management, University of Aberdeen. Financial support: The study was funded by NHS 
Grampian. NHS Grampian had no role in the design, analysis or writing of this article. The Health Services Research Unit is funded by the Chief Scientist Office of the Scottish Government Health and Social Care Directorates. Scottish Slimmers had no involvement in the design, analysis and reporting of this study. Conflict of interest: None. Authorship: M.C.W. was the principal investigator and contributed to the design, delivery and evaluation of the study as well as the preparation and critical review of this manuscript. J.I. was the research assistant working on the project and was responsible for the delivery of the study and the preparation of this manuscript. L.A. advised on study design, supervised the analysis, and contributed to the preparation and revision of this manuscript. A.A. advised on study analysis and revised drafts of this manuscript. Ethics of buman subject participation: The College of Life Sciences and Medicine Ethics Review Board, University of Aberdeen, gave ethical approval of the study. All clients gave their consent to participate.

\section{References}

1. Bromley C, Dowling S, Gray L et al. (2012) Scottish Health Survey (2012 Edition, Volume 1, Main Report). Edinburgh: The Scottish Government.

2. NHS Grampian (2012) QOF Database. http://www.gpcontract. co.uk/browse/N/Obesity/12.2012 (accessed March 2018).

3. Pittendreigh J (2010) Report on the Implementation of Healthy Helpings as a Component of the Grampian Adult Weight Management Integrated Care Pathway (ICP), August 2009-March 2010. http://www.hi-netgrampian.org/hinet/ 6467.783.786.html (accessed November 2011).

4. Aberdeen City Council (2016) Deprivation in Aberdeen City: An Analysis of the Scottish Index of Multiple Deprivation (SIMD). Briefing Paper no. 2016/05. Aberdeen: Aberdeen City Council.

5. Scottish Slimmers (2017) Homepage. http://www.scottish slimmersonline.com/ (accessed September 2017).

6. Community Pharmacy Scotland (2017) NHS Care Services I Services I Optometry Referral I Community Pharmacy Scotland and Optometry Scotland Joint Working. http:// www.communitypharmacyscotland.org.uk/nhs-care-services/ services/optometry-referral/ (accessed August 2017).
7. Community Pharmacy Scotland (2009) Guide to Direct Referral to the Out of Hours (OOH) Services. http://www.community pharmacy.scot.nhs.uk/documents/unscheduled_care/Guide_ to_Direct_Referral_V7.pdf (accessed March 2018).

8. Community Pharmacy Scotland (2018) NHS Care Services I Support I Unscheduled Care (CPUS). http://www. communitypharmacyscotland.org.uk/nhs-care-services/ support/unscheduled-care-cpus/ (accessed March 2018).

9. Porteous T, Bond C, Hannaford P et al. (2005) How and why are non-prescription analgesics used in Scotland? Fam Pract 22, 78-85.

10. Steiner D (2001) Intention to treat analysis in clinical trials when there is missing data. Evid Based Ment Health 4, 70-71.

11. Cresswell 1 \& Mander A (2014) How to use published complete case results from weight loss studies in a missing data sensitivity analysis. Obesity (Silver Spring) 22, 996-1001.

12. RandomNumberGenerator.com (2017) Random Number Generator. http://www.randomnumbergenerator.com/ (accessed August 2017).

13. Brown T, Todd A, O'Malley C et al. (2016) Community pharmacy-delivered interventions for public health priorities: a systematic review of interventions for alcohol reduction, smoking cessation and weight management, including meta-analysis for smoking cessation. BMJ Open 29, e009828.

14. Boardman HF \& Avery AJ (2014) Effectiveness of a community pharmacy weight management programme. Int $J$ Clin Pharm 36, 800-806.

15. Jolly K, Lewis A, Beach J et al. (2011) Comparison of range of commercial or primary care led weight reduction programmes with minimal intervention control or weight loss in obesity: Lighten Up randomised controlled trial. BMJ $\mathbf{3 4 3}$, d6500.

16. Ahern A, Olson A, Aston L et al. (2011) Weight Watchers on prescription: an observational study of weight change among adults referred to weight watchers by the NHS. $B M C$ Public Health 11, 434 .

17. Stubbs R, Pallister C, Whybrow S et al. (2011) Weight outcomes audit for 34,271 adults referred to a primary care/ commercial weight management partnership scheme. Obes Facts 4, 113-120.

18. Robertson C, Archibald D, Avenell A et al. (2014) Systematic reviews of and integrated report on the quantitative, qualitative and economic evidence base for the management of obesity in men. Health Technol Assess 18, issue 35, 1-424.

19. Michie S \& Johnston M (2011) Behaviour change techniques. In Encyclopedia of Behavioural Medicine, pp. 1005-1009 [MD Gellman and JR Turner, editors]. New York: Springer. 